\title{
Negative disclosures in corporate social responsibility reporting
}

\author{
Sabine A. Einwiller
Department of Communication, University of Vienna, Vienna, Austria, and \\ Sabine A. Einwiller
Department of Communication, University of Vienna, Vienna, Austria, and \\ Craig E. Carroll \\ OCR Network, New York, USA
}

\begin{abstract}
Purpose - This study aims to reveal the quantity, quality and cultural differences of negative corporate social performance (CSP) disclosures in large firms' corporate social responsibility (CSR) reports. Firms are expected to be transparent about the impacts and outcomes of their CSP. A central aspect of transparency is balance, which means disclosing both positive and negative CSP.

Design/methodology/approach - Content analysis was applied to 75 CSR reports of large firms chosen from the Forbes Top 500 list. The firms belong to three cultural clusters: Anglo, Confucian Asia and Germanic/ Nordic Europe.

Findings - Firms made few negative CSP disclosures, yet the quantity of negative CSP disclosures varied among cultural clusters. Reports from Germanic/Nordic Europe showed the highest number of negative CSP disclosures, reports from Confucian Asia showed the lowest number and the Anglo cluster's number fell in between. The Asian firms communicated corrective actions more often than firms from the other clusters.

Research limitations/implications - This study focused on negative CSP disclosures in the CSR reports not omitting negative CSP. The practice of self-laudatory CSR communication decreases the likelihood that relevant stakeholders will believe what firms report about.

Originality/value - Studies on the quality and quantity of negative disclosures are rare; by examining cultural differences, this study contributes to the limited body of knowledge.
\end{abstract}

Keywords Disclosure, Content analysis, CSR reporting, Culture, Transparency, Global reporting initiative Paper type Research paper

\section{Introduction}

For many firms around the world, reporting on corporate social performance (CSP) has become an accepted method of addressing corporate social responsibility (CSR) expectations from society and corporate stakeholders. CSR can be viewed as "a response to the specific demands of largely external stakeholders" (Basu and Palazzo, 2008, p. 122), while CSP represents the measurable impacts and outcomes that come from a firm's CSR actions (Wood, 2010). CSR reporting is mainly concerned with demonstrating a firm's CSP. By sharing CSP disclosures over and above their financial reporting obligations, firms attempt to legitimize their behavior (e.g. Deegan, 2002; Neu et al., 1998).

In 2017, 93 percent of the world's largest 250 firms issued CSR reports (KPMG, 2017)[1]; however, the global proliferation in CSR reporting has not led to an increased belief in firms' intention to take CSR seriously and to report transparently. In fact, the rise in CSR communication and reporting corresponds with even more skepticism and scrutiny from stakeholders (Elving et al, 2015; Waddock and Googins, 2011). One central point of criticism concerns the selectivity in CSR reporting in terms of what is reported on (Coombs and Holladay, 2013). Devin (2016) speaks of "half-truths," in that firms communicate technically

(C) Sabine A. Einwiller and Craig E. Carroll. Published by Emerald Publishing Limited. This article is published under the Creative Commons Attribution (CC BY 4.0) licence. Anyone may reproduce, distribute, translate and create derivative works of this article (for both commercial and non-commercial purposes), subject to full attribution to the original publication and authors. The full terms of this licence

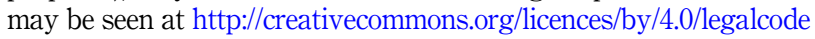

Received 16 May 2019 Revised 24 September 2019 Accepted 11 October 2019 (n) 
CCIJ

25,2

320

correct, truthful information in their CSR reports, but omit key information, like failures and setbacks.

Selective reporting and embellishment increase skepticism and prevent transparency, which requires that "all legally releasable information-whether positive or negative in nature" (Rawlins, 2009, p. 75) is made available. Enhancing transparency is a declared goal of the Global Reporting Initiative (GRI) framework; balance, which involves disclosing "positive and negative aspects of the organization's performance" (GRI, 2015, p. 17), is one of the framework's six principles of report quality. With the GRI's acceptance and its focus on transparency and balance in mind, the research question arises as to whether firms follow the principle of balance and how much of the reports' contents are negative.

As negative incidences like failures, setbacks and self-criticism are value-relevant and important material to firms' stakeholders, adhering to the principle of balance in reporting i.e. disclosing both negative and positive aspects - is crucial to successful CSR reporting. However, research on negative CSP disclosures is limited. Hahn and Lülfs (2014) qualitatively analyzed CSR reports by US and German firms and identified six legitimation strategies that firms apply when reporting negative aspects. Qualitative research has also been used to unveil impression management and neutralization techniques in CSR reports by firms in the energy (Talbot and Boiral, 2018) and mining (Boiral, 2016) sectors. These studies provide indepth insights into the rhetorical strategies firms use to rationalize, justify or conceal their impacts to limit negative disclosures. In terms of quantity, Holder-Webb et al. (2009) examined a sample of US firms to research various types of public CSP-related discourses in 2004; they concluded that the reporting practices were predominantly self-laudatory. Similar conclusions were reached for environmental reporting practices of Australian firms (Deegan and Gordon, 1996; Deegan and Rankin, 1996).

The most recent findings on the quantity of negative CSP disclosures come from outside academia. Drawing on their 2013 analysis of CSR reports published by the world's largest 250 firms (Fortune ranking), KPMG (2013) concluded that most firms offer limited or no information on challenges, setbacks and failures. This analysis found that only 23 percent of the reports are balanced, and that reports by European firms were the most balanced while those by Asia Pacific firms were the least balanced. In their 2015 report, KPMG (2015) noted no improvement in average reporting quality. These findings suggest limited adherence to the principle of balance, as well as geographical and cultural differences.

In this study, we extend the limited scholarly research on negative CSP disclosures in CSR reports in three important ways. First, we determine the amount of negative disclosures in CSR reports from large firms. Second, we analyze the topics communicated and the legitimation strategies used when reporting on negative CSP. Third, we shed light on the role of culture in moderating the quantity and quality of negative CSP disclosures, using three cultural clusters: Anglo countries, Confucian Asia and Germanic/Nordic Europe (Gupta et al., 2002).

\section{Literature review and hypothesis development \\ Legitimacy and CSR reporting}

The legitimacy theory is a widely used framework that is often used to explain disclosures about firms' CSP. Establishing firms as part of a broader social system, the legitimacy theory suggests that firms do not have an inherent right to resources or even to existence. Society assigns legitimacy to firms (Deegan, 2002), and legitimacy is vital to their survival (Dowling and Pfeffer, 1975). In the organizational context, Suchman (1995) defined legitimacy as the perception that a firm's actions are in line with the perceivers' socially constructed system of norms, values, beliefs and definitions. Because stakeholders do not have access to organizational decision-making, they must have transparency to see that organizations are acting in line with their expectations. 
One way organizations signal transparency is through CSR reporting (Carroll and Einwiller, 2014). The legitimacy theory sees CSR reporting as a way for organizations to answer claims coming from society. Through the process of legitimation, which substantiates organizational legitimacy (Kaplan and Ruland, 1991), "organizations seek to establish congruence between the social values associated or implied by their activities and the norms of acceptable behavior in the larger system they are a part" (Dowling and Pfeffer, 1975, p. 122). CSR reports provide information to a number of stakeholders who control different resources and pursue various interests and who, thus, demand disclosure from the firm. CSR reports enable firms to legitimize themselves, their behavior and the effects of their behavior (Brown and Deegan, 1998; Neu et al., 1998; O’Donovan, 2002).

\section{Negative CSP disclosure}

Corporate behavior with negative ecological or social impact can endanger corporate legitimacy if stakeholders perceive it to not be in line with societal norms and values (Hahn and Lülfs, 2014). In addition, empirical research shows that shareholders benefit from positive CSP, and that negative CSP carries idiosyncratic risk (Mishra and Modi, 2013). This leads firms to tend to not disclose the negative aspects related to their CSP. However, without disclosing some setbacks or failures, firms can encounter increased skepticism regarding the reliability and usefulness of their CSR reports. An excess of positive and whitewashed information holds little value if the report does not foster corporate accountability (Carroll and Olegario, 2019) or provide a fair and authentic picture of a firm's CSP (Hahn and Lülfs, 2014).

Negative CSP disclosures are necessary to attain corporate transparency (Rawlins, 2009), yet regulatory requirements dictating that firms make negative CSP disclosures are limited. This is where projects such as the GRI - the most widely used voluntary framework for CSR reporting (Sethi et al., 2017) - become important. The GRI explicitly requests positive and negative disclosures in CSR reporting, which the GRI refers to as balance. Balance does not mean that firms need to report an equal number of positive and negative aspects, but rather that negative aspects need to be disclosed in addition to highlighting the firm's positive actions and impacts.

Drawing on Hahn and Lülfs's (2014) definition of negative aspects in CSR reporting, we define a negative CSP-related disclosure as any corporate statement referring to factual corporate conduct regarding social, environmental or economic aspects, which had or have a potential or actual negative impact on the realization of sustainability. We note two differences between our definition and the former.

First, Hahn and Lülfs's definition includes potential corporate conduct that had or has a (potentially) negative impact, beyond simply factual corporate conduct, while our focus is on negative disclosures about actual CSP (Liston-Heyes and Ceton, 2009). Because information regarding potential negative conduct does not constitute actual CSP (negative CSP such as setbacks, failures or unmet goals), a negative statement involving speculation, uncertainty or hedging would not count as a negative CSP disclosure in our definition.

Second, Hahn and Lülfs focused on negative environmental and social aspects but not economic aspects, as the latter was assumed to be covered in traditional financial reporting. As our study concerns the quantity of negative CSP disclosures across the full range of CSR reporting, the inclusion of economic aspects is necessary for this study to be comprehensive.

Despite the role of negative CSP disclosures in transparency, firms focus on the disclosure of gains and successes, or "good news," in their CSR reports (Deegan and Gordon, 1996; Deegan and Rankin, 1996; Holder-Webb et al., 2009; KPMG, 2013). We assume this occurs because they fear that disclosing setbacks, failures or unmet goals puts legitimacy - and, in the case of publicly traded firms, financial performance - at risk (Mishra and Modi, 2013). In fact, research shows that negative information is highly diagnostic because people believe it to be more characteristic of actors who belong in negative categories (Skowronski and Carlston, 1989).
Corporate social responsibility reporting 
CCIJ

25,2

322

However, research on the effects of two-sided messages has revealed that disclosing negative information in addition to positive information has positive effects on people's judgments of source credibility (Kamins and Assael, 1987; Smith and Hunt, 1978). Wagner et al. (2009) found that firms can reduce perceptions of corporate hypocrite when they use an inoculation strategy, i.e. when firms anticipate negative information will be discovered or released by other parties, they proactively disclose the information and offer refuting counterarguments in advance. Thus, it remains unclear whether firms disclose a lot or a little negative CSP in their CSR reports.

Therefore, our first research question is:

$R Q 1$. How much negative CSP disclosure exists in firms' CSR reports?

The GRI recommends that firms externally assure their CSR reports. They posit that using external, independent reviews of sustainability management processes and disclosures will increase the robustness, accuracy and trustworthiness of CSP disclosures, as well as build confidence in the areas of governance, management and stakeholder relations (GRI, 2013). Despite some scholars' criticism concerning ambiguity and diversity in the criteria and scope of external assurance, as well as the independence of assurance practitioners (e.g. Deegan et al., 2006; Wilson, 2003), we assume that external assurance has the effect of balancing CSR reports.

H1. The amount of negative CSP disclosures in CSR reports of firms is higher in reports that are externally assured.

Reporting frameworks like the one issued by the GRI offer a comprehensive list of topics and indicators. The GRI framework versions G3.1 and G4 asks firms to report on the following areas of impact: economic, environmental (subdivided into materials and products and services) and social (subdivided into labor practices, human rights, society and product responsibility). The GRI provides several performance indicators for each aspect. Considering the number of indicators for each of the aspects (economic $=9$, environmental $=34$, social $=48$ ), a focus on the social and environmental aspects becomes clear. Thus, it is likely that most negative CSP disclosures will involve social and environmental aspects.

Within these two areas, certain disclosures are mandatory. For example, in environmental reporting, various governmental bodies require firms to report their emissions of greenhouse gases (GHG). In social reporting, mandates include aspects of organizational safety and health, such as workplace fatalities and injuries. To show compliance with these norms, firms align their disclosures to the demands of the agencies to which they provide the report, a process that has been called disclosure alignment (Carroll and Einwiller, 2014). Firms need to show that they understand what is asked of them and that they are willing to be accountable.

In support of the argument that regulatory pressures from the state induce greater disclosure, Freedman and Jaggi (2005) showed that firms from the countries that have ratified the Kyoto Protocol report more detailed disclosures on climate change issues. Similarly, Reid and Toffel (2009) found that firms' participation in the Carbon Disclosure Project positively corresponded to greater state-level pressure regarding climate change concerns. Thus, we assume that most negative CSP disclosures will deal with those topics governed by national or transnational regulations.

H2. Negative CSP disclosures in CSR reports of firms mostly refer to topics on which firms are mandated to report by national or transnational regulations.

\section{The influence of culture on negative CSP disclosures}

Research on cultural differences in CSR reporting has mainly focused on similarities and differences in publishing a report and the general topics reported on (e.g. Kolk, 2005, 2008). Our comparison examines large firms headquartered in three economically powerful cultural 
clusters (Gupta et al., 2002): Anglo countries, Confucian Asia and Germanic/Nordic (G/N) Europe[2]. These clusters come from the ten clusters that were determined based on data from the GLOBE study pertaining to cultural values and beliefs (House et al., 2004). The results of this study showed that cultural cluster effects account for more than two-third of intersocietal differences in values and certain practices, such as institutional collectivism. In particular, differences in individualism-collectivism and the role of face suggest cultural variations in the quantity of negative CSP disclosures.

Individualism-collectivism is likely the most widely studied dimension of cultural variability. Cultures that score high on the individualism end of the continuum emphasize personal goals over group goals and stress values that benefit the individual person (e.g. Triandis, 1995). By contrast, collectivist societies centralize social units with common fate, common goals and common values; the primary value is harmony with others Triandis (1995).

Individualism typifies the Anglo-American culture (Hofstede et al., 2010); Hofstede and colleagues suggest that the USA ranks highest in individualism, followed by the UK and - at some distance - Canada and The Netherlands. While still considered individualistic, Scandinavian and Germanic countries fall more to the middle on this continuum (http://geerthofstede.com/national-culture.html). Collective values, social relationships and harmony are strongest in cultures influenced by Confucianism such as China, South Korea and Japan (e.g. Zhang et al., 2005), although intercultural differences exist; according to a meta-analysis by Oyserman et al. (2002), China is highest in collectivism, followed by South Korea and Japan.

Considering the value of the collective in collectivist societies, we would expect that firms in these societies are more likely to disclose information that stakeholders and society deem material, including negative CSP. However, other characteristics of collectivist cultures - like preserving social harmony and keeping face - would suggest the opposite.

While people in all cultures try to keep face in most interactions, the importance of face is higher in collectivist societies (Varner and Beamer, 2005). Face is understood as a claimed sense of favorable social self-worth and an estimated other-worth in an interpersonal situation (Ting-Toomey and Kurogi, 1998). Face is kept or lost by complying with or violating the behavior expected of a person. In collectivistic cultures, keeping structural harmony is of importance (Bond and Hwang, 1986). Here, attention is not just paid to preserving one's own face but also the face of superiors and of the group/firm. Because of this greater cost of losing face and of disrupting harmony, firms from Confucian Asian countries might make fewer negative CSP disclosures than firms from individualistic cultures.

H3. CSR reports for firms from G/N European and Anglo countries contain more negative CSP disclosures than reports for firms from Confucian Asian countries.

When firms disclose negative CSP, they jeopardize face and thus social harmony. To preserve or restore face and legitimacy (Hahn and Lülfs, 2014), firms may apply certain legitimation strategies in their negative CSP disclosures. Drawing on the literature of image restoration, legitimacy, impression management and strategic disclosure, as well as conducting in-depth qualitative content analysis of CSR reports by German and US firms, Hahn and Lülfs (2014) determined various legitimation strategies that firms use when reporting on negative CSP. In addition to the strategy of simply mentioning the negative CSP as a fact, without giving any explanation or justification (which the authors call "indicating facts"), Hahn and Lülfs differentiate the following five strategies of legitimizing shortcoming in CSP disclosures:

(1) Corrective action: Ideas, intent or measures are offered for how to tackle or avoid the negative aspect in the future, or information is provided on measures already undertaken to correct the problem.

(2) Rationalization: Negative aspects are explained and justified by referring to the utility or function of specific actions or practices. This includes multiple forms of
Corporate social responsibility reporting

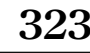


CCIJ

25,2

324

instrumental rationalization (highlighting benefits, functions or purposes) and theoretical rationalization (emphasizing some form of "normal" or "natural" behavior or development).

(3) Abstraction: Existence of a negative aspect is generalized as being prevalent throughout a whole industry.

(4) Marginalization: Relevance of the negative aspect is downplayed.

(5) Authorization: A reference is made to a higher authority to deliver external explanations, validations and judgments of the negative aspect. Here, third parties or authorities provide an apparently more objective justification for the incident.

While Hahn and Lülfs (2014) did not find any notable differences between German and US reports in the use of these legitimation strategies, we can expect differences between western firms and Confucian Asian firms. Because face is more important in collectivist than in individualist societies (Ho, 1976; Varner and Beamer, 2005), it can be expected that firms based in Confucian Asian countries more often apply legitimation strategies to protect face and legitimacy. This means that they offer a justification for a setback or failure (authorization and rationalization), or that they generalize (abstraction) or marginalize (marginalization) the negative aspect. We expect that firms from Confucian Asian cultures will more often communicate a corrective action by which the firm shows the ability to improve and to prevent negative impacts in the future.

H4. Firms from Confucian Asian countries are more likely to apply the legitimation strategies of (a) corrective action, (b) rationalization, (c) abstraction, (d) marginalization and (e) authorization when disclosing negative CSP than are firms from $\mathrm{G} / \mathrm{N}$ European or Anglo countries.

\section{Methodology \\ Sample}

The population from which the sample was drawn was the top 500 firms listed in 2014's Forbes Global 2000 (Forbes, 2014), with headquarters in the largest economies in the Anglo (Canada, UK, USA), Confucian Asia (China, Japan, South Korea) and G/N Europe (Germany, The Netherlands, Switzerland/Denmark, Finland, Norway, Sweden) clusters. CSR reports were downloaded from the firms' websites. For a CSR report to be considered for the sample, it had to be available as a digital downloadable PDF document. For the sake of comparability, we did not include integrated reports, as these would have disproportionately biased the economic aspects. We selected reports wholly or partially concerning the 2014, with a published English version. In case of a report in multiple languages, all analyses refer only to the English language pages. After downloading all available reports that met the criteria, we drew a random sample of 25 reports per cultural cluster $\left(N_{\text {total }}=75\right)$.

Table I gives an overview of the sample. Because of the high representation of firms from the USA, Japan and Germany in the Forbes Top 500, US firms dominated the Anglo cluster, Japanese firms dominated the Confucian Asian cluster and German firms dominated the G/N Europe cluster. Most firms were in the sectors of financial services, automobile and oil and gas/energy/raw materials. The sectors were evenly distributed across cultural clusters. The relationship between industry sector and cultural cluster is not significant, $\chi^{2}(2$, $N=75)=1.065, n . \mathrm{s}$.

In most reports, the firm claimed to have followed either GRI3/GRI3.1 (31 percent) or G4 (51 percent), while 5 percent claimed to have followed GRI without mentioning which version. A total of 13 percent of the firms $\left(n_{\mathrm{ANG}}=5, n_{\mathrm{CA}}=4, n_{\mathrm{GNE}}=1\right)$ did not mention adhering to any reporting standard. 


\begin{tabular}{|c|c|c|c|c|c|c|c|c|c|c|c|c|c|}
\hline \multirow[b]{2}{*}{ Sector } & \multirow[b]{2}{*}{$\sum$} & \multicolumn{3}{|c|}{$\begin{array}{c}\text { Confucian } \\
\text { Asia }(n=25)\end{array}$} & \multicolumn{3}{|c|}{ Anglo $(n=25)$} & \multicolumn{5}{|c|}{ G/N Europe $(n=25)$} & \multirow{2}{*}{$\begin{array}{r}\text { Corporate } \\
\text { social } \\
\text { responsibility }\end{array}$} \\
\hline & & $\mathrm{JP}$ & $\mathrm{CN}$ & $\mathrm{KR}$ & US & CA & UK & $\mathrm{DE}$ & $\mathrm{CH}$ & $\mathrm{NL}$ & $\mathrm{SE}$ & NO & \\
\hline Financial services & 17 & 1 & 3 & & 1 & 4 & 1 & 1 & 1 & & 4 & 1 & reporting \\
\hline Automobile & 11 & 7 & & & 1 & & & 3 & & & & & \\
\hline Oil and gas, energy, raw materials & 10 & & 2 & & 3 & & 2 & 2 & & 1 & & & \\
\hline Retail, consumer goods & 9 & 3 & & & 2 & & & 1 & 1 & 1 & 1 & & 325 \\
\hline Telecommunication & 8 & 1 & 1 & & 1 & & 1 & 2 & 1 & & 1 & & \\
\hline Computer, electronics & 8 & 2 & & 1 & 5 & & & & & & & & \\
\hline Insurances & 4 & 2 & & & & & & 2 & & & & & \\
\hline Chemicals, pharmaceuticals & 3 & & & & 1 & & 1 & & 1 & & & & \\
\hline Conglomerates, construction & 3 & & 1 & & 1 & & & & 1 & & & & \\
\hline Other & 2 & 1 & & & 1 & & & & & & & & \\
\hline$\sum$ & 75 & 17 & 7 & 1 & 16 & 4 & 5 & 11 & 5 & 2 & 6 & 1 & \\
\hline $\begin{array}{l}\text { Note(s): JP = Japan, CN = China, } \\
\mathrm{DE}=\text { Germany, CH = Switzerland }\end{array}$ & $\begin{array}{l}\mathrm{KR}= \\
\mathrm{NL}=\end{array}$ & $\begin{array}{l}\text { Sou } \\
\text { The }\end{array}$ & $\begin{array}{l}\text { h Kor } \\
\text { Nethe }\end{array}$ & $\begin{array}{l}\text { ea, US } \\
\text { rlands, }\end{array}$ & $\begin{array}{l}=\mathrm{US} \\
\mathrm{SE}=\end{array}$ & $\begin{array}{l}\text { A, CA } \\
\text { Swec }\end{array}$ & $\begin{array}{l}=\mathrm{Ca} \\
\text { en, NC}\end{array}$ & $=\mathrm{N}$ & $\begin{array}{l}\mathrm{JK}= \\
\text { rway }\end{array}$ & Unite & King & dom, & $\begin{array}{l}\text { Table I. } \\
\text { Sample }\end{array}$ \\
\hline
\end{tabular}

\section{Procedure and measures}

We applied a combination of qualitative and quantitative manual content analysis in two phases. In Phase 1, a group of 20 coders (master's level students majoring in communication science) were extensively trained to identify negative CSP disclosures in the reports; in Phase 2, they coded the manifest and latent content (Potter and Levine-Donnerstein, 1999). In the first phase, a team of two coders (ten teams in total) closely read each report to find passages with negative CSP disclosures per the definition laid out above: any corporate statement referring to factual corporate conduct regarding social, environmental or economic aspects, which had or have a potential or actual negative impact on the realization of sustainability. A negative CSP disclosure was considered complete if it referred to one subtopic within a topic area (Table II), and it usually spanned 2-4 sentences. Any existing supplementary tables or figures on the same topic were coded as part of the same disclosure.

The total number of pages relevant to the analyses was 6,345. (Pages that were excluded included title and back page, table of contents, dividing pages, pages with tables or figures forming more than half of the page and publishing information/flag.) The length of the reports ranged from 17 to 232 relevant pages $(M=85, \mathrm{SD}=47)$. The focus of the analyses was the narrative, i.e. the text. However, we considered tables and figures when they formed less than 50 percent of a page or when they complemented the narrative, although we excluded tabular overviews included at the end of a report.

Potential content had to meet several criteria. First, the negative impact needed to be manifest content (Potter and Levine-Donnerstein, 1999) within the passage, without any further exploration or speculation. For example, the statement "The total turnover rate was 12.4 percent" alone was not considered negative, but it was if it was accompanied by a statement that this was an increase compared to the previous year(s) and/or that the firm did not reach its goal of a lower turnover rate. Second, coders were instructed to only select content that could be considered negative regardless of the cultural background. For example, the statement "We use polyethylene terephthalate (PET) for water packaging and ready-to-drink products in a number of countries" was not considered negative, even though PET is often regarded as unsustainable in European countries, as in other countries, its lightweight quality actually makes it a sustainable packaging option.

Third, descriptions of negative externalities (e.g. earthquakes, financial crisis) were only considered negative when the firm mentioned being negatively affected by them (e.g. "the tsunami caused production losses") or having contributed to them (e.g. "We too have a 
CCIJ
25,2

Labor practices

\begin{tabular}{|c|c|c|c|}
\hline Topic area & Subtopic & $n$ & $\%$ of total \\
\hline \multirow{4}{*}{ Environment } & & 245 & 35 \\
\hline & Emissions, discharge of noxious substances in the air (e.g. $\left.\mathrm{CO}_{2}\right)$ & 88 & 13 \\
\hline & Consumption of resources & 85 & 12 \\
\hline & Contamination or destruction of soil, water, biosphere; waste & 32 & 5 \\
\hline \multicolumn{2}{|c|}{ Labor practices } & 200 & 29 \\
\hline & Accidents, accident rate, cases of illness and death & 66 & 9 \\
\hline & Negative incidents/conduct regarding labor practices in supply chain & 57 & 8 \\
\hline & $\begin{array}{l}\text { Non-compliance with working norms, disciplinary violations within } \\
\text { company }\end{array}$ & 19 & 3 \\
\hline & Employee dissatisfaction & 14 & 2 \\
\hline \multicolumn{2}{|c|}{ Human rights and society (combined) } & 78 & 11 \\
\hline & Human rights violations regarding societies where company operates & 19 & 3 \\
\hline & Corruption cases & 8 & 1 \\
\hline \multirow[t]{3}{*}{ Economy } & & 69 & 10 \\
\hline & Development of turnover, profit, sales & 15 & 2 \\
\hline & Fines, monetary sanctions & 14 & 2 \\
\hline \multicolumn{2}{|c|}{ Product responsibility } & 57 & 8 \\
\hline & Customer dissatisfaction & 24 & 3 \\
\hline \multirow{3}{*}{ Other } & Product defects, product contamination & 10 & 1 \\
\hline & & 53 & 7 \\
\hline & Image or reputation problems & 13 & 2 \\
\hline
\end{tabular}

Table II.

Topic areas and subtopics of negative CSP disclosures $(H 3)$

Note(s): Adjusted for recurrent topics; listed are only the most frequently mentioned subtopics

responsibility for the financial crisis"). Fourth and finally, statements in the subjunctive mood (e.g. "Our reputation may be instantly tarnished by corporate scandals, legal infractions or product quality issues") were not considered negative disclosures.

After reading, the two coders compared their finds and discussed inconsistencies. When the coders could not agree as to whether an aspect qualified as negative, a third coder was called in to break the tie. The authors then double-checked the passages chosen by the coders to see if they fit with the definition of negative CSP disclosure. At the end of this first phase, a total of 783 negative CSP disclosure passages were identified.

In the second phase, we developed a codebook with nine manifest and seven latent categories (see Appendix). For topic area, we adapted the categories from the 2013 GRI guidelines. To code the legitimation strategies, we drew on Hahn and Lülfs' (2014) definitions and examples. Examples for the latent categories represented in the current data are included in the Appendix. Based on the data, the coding of the strategy "corrective action" was enhanced, discerning three levels of corrective action: (1) an imprecise or vague provision of a future corrective action, (2) a precise statement regarding future or partially completed corrective actions and (3) a disclosure that the problem was already corrected. Thus, the content analysis is mainly concept-driven, but is in some parts, also data-driven. Of the negative passages, one-third $(n=250)$ were double-coded and tested for intercoder reliability. Reliability tests for all categories showed satisfactory results (all variables Holsti $\geq 0.88$ and Cohen's Kappa $\geq 0.80$ ).

\section{Results}

The unit of analysis for answering/testing the research question and hypotheses was either the whole report (RQ1, H1, H3) or the individual negative passages (H2, H4).

\section{Amount of negative disclosures}

The absolute number of negative CSP disclosures within a CSR report ranged from 0 to 55 $(M=10.5, \mathrm{SD}=9.88)$; however, more relevant than the absolute number is the proportion of 
negative content within a report. We determined this by first assessing the proportion a negative CSP disclosure took up in a page, then adding up the proportions in a report and then dividing that sum by the total number of relevant pages. Our results show that, on average, 0.9 percent $(M=0.00884, \mathrm{SD}=0.0071)$ of the reports' content is negative. This answers RQ1, indicating that the volume of negative CSP disclosures in the CSR reports of large firms is very small.

We conducted an analysis of variance (ANOVA) and planned comparisons tests to investigate the hypothesis that firms from individualistic cultures made more negative CSP disclosures than firms from collectivistic cultures. ANOVA reveals a significant effect of cultural cluster on the volume of negative content $\left(M_{\mathrm{CA}}=0.0061, \mathrm{SD}=0.0048\right.$, $M_{\mathrm{ANG}}=0.0082, \mathrm{SD}=0.0066 ; M_{\mathrm{GNE}}=0.0122, \mathrm{SD}=0.0084 ; F[2,72]=5.31, p<0.01$, $\left.\eta^{2}=0.16\right)$. Comparisons between the groups show no difference between the Confucian Asian and Anglo cluster $(t=1.32, \mathrm{df}=43.7, p=n . \mathrm{s}$.), a marginally significant difference between the Anglo and $\mathrm{G} / \mathrm{N}$ Europe cluster $(t=1.9, \mathrm{df}=45.4, p<0.07)$ and a significant difference between the Confucian Asian and G/N Europe $(t=3.2, \mathrm{df}=38, p<0.01)$. Thus, $\mathrm{H} 3$ - stating that firms from $\mathrm{G} / \mathrm{N}$ Europe and Anglo countries disclosed more negative CSP than firms from Confucian Asian countries - is only partially confirmed.

\section{The role of external assurance}

External assurance by an independent auditor existed for 65 percent $(N=49)$ of the reports; 28 percent $(n=21)$ did not experience external assurance. Five of the firms (four of them Japanese) included a third-party opinion by external experts instead of external assurance. Of the 21 not externally assured CSR reports, about half (52 percent) were for firms from Anglo countries (USA or Canada), followed by firms from Asian (29 percent) and G/N European (19 percent) countries.

Analysis of covariance (ANCOVA) was conducted to test the hypothesis that externally assured reports contain more negative CSP disclosures than those that are not externally assured. Two dummy-coded variables for cultural cluster served as covariates to control for culture effects. The data reveal that external assurance significantly influences the proportion of negative CSP disclosures: externally assured reports include more negative CSP disclosures $(M=0.01007, \mathrm{SD}=0.00749)$ than reports that were not externally assured $\left(M=0.005999, \mathrm{SD}=0.005123 ; F[1,66]=3.17, p=0.05, \eta^{2}=0.06\right)[3]$. Thus, $\mathrm{H} 1$ is confirmed, although the effect barely reaches significance.

\section{Topics of negative CSP disclosures}

We found a total of 702 negative topics (new aspects, i.e. repetitive topics were only counted once): 35 percent related to the environment, 29 percent to labor practices, 11 percent to human rights and society issues, 10 percent to economic issues and 8 percent to product responsibility. Other topics - e.g. criticism regarding CSR reporting methods or reputation problems - accounted for 7 percent of the negative volume. Table II gives an overview of the topics and the most frequently occurring subtopics addressed in the negative passages. Confirming H2, the data show that the aspects for which disclosure is regulated by governmental bodies (GHG emissions and workplace fatalities/injuries) were reported most often.

\section{Legitimation strategies}

H4 states that firms from Confucian Asian countries are expected to use legitimation strategies more often than firms from the other two cultural clusters. Table III provides an overview of the results on the use of such strategies.
Corporate social responsibility reporting 


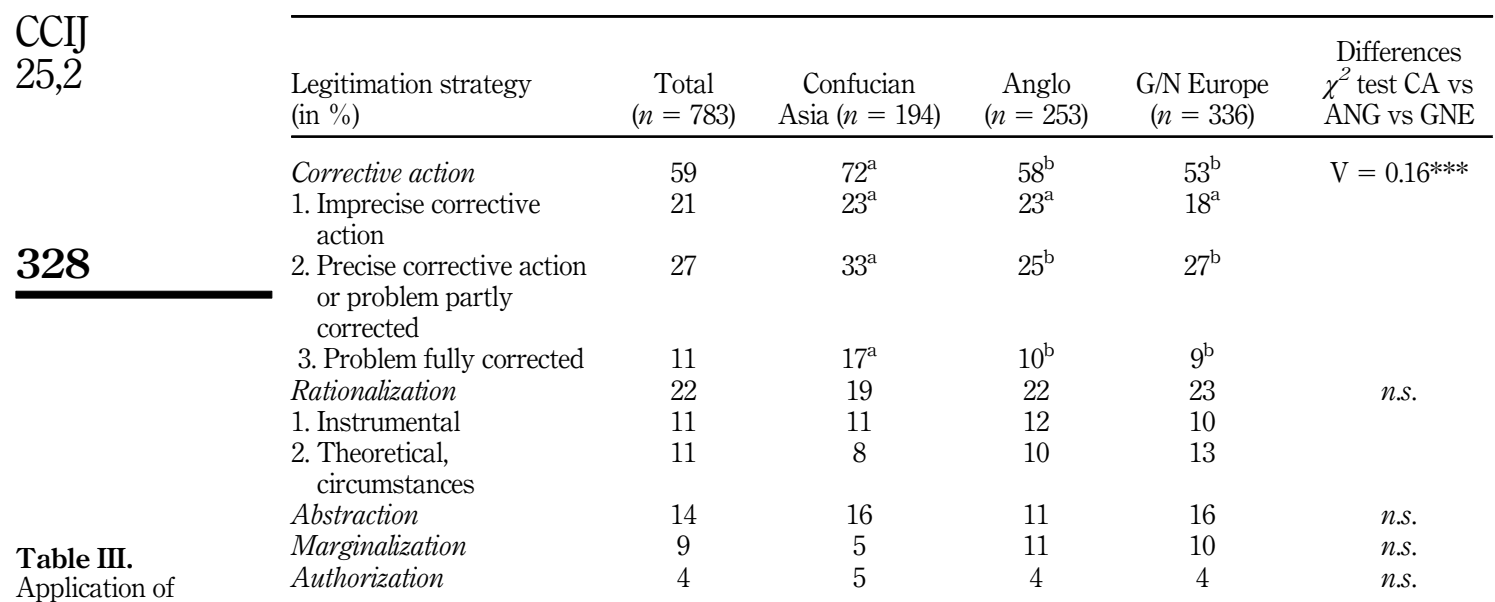

legitimation strategies $\quad$ Note(s): $\mathrm{V}=$ Cramer's $\mathrm{V}, n . \mathrm{s} .=$ non-significant, $* * * p<0.001$; different superscripts indicate significant (H5a-e) difference at $p<0.05$ between the regions (z-score test, https://www.socscistatistics.com/tests/ztest/)

Corrective action was the legitimation strategy applied most often (59 percent). In line with $\mathrm{H} 4 \mathrm{a}$, firms from the Confucian Asian cluster (72 percent) offered ideas, intents or measures for how they had or would tackle or avoid negative CSP in the past and future more often than did firms from the Anglo cluster (58 percent) and the G/N Europe cluster (53 percent). To test whether the differences between these proportions are significant, we applied the $z$-score test, which is used to test whether two groups differ significantly on some single binary characteristic. The results reveal that firms from Confucian Asian countries mentioned corrective actions significantly more often than firms from the Anglo cluster or the G/N Europe cluster (CA vs Anglo, $z=3.27, p<0.01$; CA vs GN/E, $z=5.57, p<0.01$ ), while the Anglo and G/N Europe clusters did not differ.

Comparisons of how firms communicated their corrective actions substantiated H4a. Firms from the Confucian Asian cluster were more precise when communicating corrective actions (CA vs Anglo, $z=2.22, p<0.05$; CA vs GN/E, $z=3.14, p<0.01$ ), and they communicated corrective actions that were already fully completed more frequently than firms from the other two clusters (CA vs Anglo, $z=2.12, p<0.05$; CA vs GN $/ E, z=3.12$, $p<0.01)$. We found no meaningful difference in proportionate mentions of imprecise corrective actions. All other legitimation strategies were used less often, with no differences among the cultural clusters. Thus, only H4a - concerning cultural differences in using the corrective action legitimation strategy - is confirmed.

\section{Discussion}

Our study reveals that the principle of balance, as laid out by the GRI, is largely disregarded by the large firms in our sample. On average, less than 1 percent of the report content disclosed failures, shortcomings or setbacks. Of the 75 reports analyzed, six included solely positive content. Although face and harmony are considered more important in cultures influenced by Confucianism, we find that firms from the Anglo cluster made just as few negative CSP disclosures. Only in reports by firms in G/N European countries did we find a significantly higher proportion of negative disclosures.

This minimal disclosure of failures, shortcomings or setbacks is likely due to a fear of risking legitimacy, losing reputation or incurring other negative consequences (Mishra and 
Modi, 2013). Firms may also fear that disclosing negative CSP endangers their interests, as competitors might misuse the disclosures for their own advantage. If many firms in a sector withhold negative CSP, a fully transparent firm could suffer a disproportionate amount of damage (Dubbink et al., 2008). Thus, transparency is a double-edged sword, seen by many as advantageous but by others as risky - above all by the reporting firm.

An alternative explanation for the limited amount of negative CSP disclosures is that the large firms in our sample operated ideally during the reporting period, with little to no negative CSP to disclose. However, as negative CSP here refers to any corporate conduct regarding social, environmental or economic aspects that had or has a potential or actual negative impact, it is unlikely that most large multinational firms had little or nothing to report. It is more likely that our results indicate that firms omit disclosing certain negative impacts and/or report half-truths (Devin, 2016). However, this practice of self-laudatory CSR communication decreases the likelihood that relevant stakeholders will believe what firms report, especially against the backdrop of decreasing trust in firms (Waddock and Googins, 2011).

The GRI claims that external assurance can increase confidence in the quality of sustainability performance data, making it more likely that the data will be relied on and used for decision-making (GRI, 2013). Although we did not measure confidence in the data, we show that external assurance correlates with more negative CSP disclosures and thus morebalanced reporting, which enhances transparency and confidence. However, the amount of negative CSP disclosures in reports with external assurance was still very low.

Less external assurance occurs in North America (USA and Canada): more than half of the reports in our sample were not externally assured. This may explain our finding that Anglo reports did not differ from Confucian Asian reports in terms of quantity of negative CSP disclosures. A study by GRI in collaboration with the Governance and Accountability Institute (G\&A) showed that only 10 percent (26 out of 269) of GRI-based sustainability reports in the USA obtained external assurance in 2011, while internationally, that rate was 38 percent (GRI and G\&A, 2013). Although the sample in our study differs from that of the GRI/G\&A study, our findings show that readiness to obtain external assurance for a CSR report is higher among the largest firms than among all firms that prepare a GRI-based report.

A closer look at the topics of negative CSP disclosures reveals even more. Our results show that most of the negative CSP disclosures relate to the environment and to working conditions, with emissions, accidents and health disclosures topping the list. In the countries included in our sample, large firms are obliged to report their GHG emissions and/or energy consumption; similarly, reporting on occupational accidents and illnesses (as the International Labor Organization (ILO) promotes) is mandatory in many countries. It seems that firms disclose negative CSP that will inevitably become known while hiding negative CSP that is less likely to go public without volitional disclosure.

This raises the question whether negative CSP disclosures are based on volition or whether firms simply use mandatory disclosures to try to create an appearance of balance and transparency. Firms seem to engage in transparency signaling - an effort to nonverbally signal transparency - and disclosure alignment - a firm's public attempts to align their disclosure practices with the expectations/standards of regulatory guidelines (Carroll and Einwiller, 2014). Firms adapt the report to the expectations of their publics so that the firm's stakeholders and constituents will construe the firm as legitimate. We contend that firms disclose negative CSP that will inevitably become known while hiding negative CSP that is less likely to go public without their volitional disclosure. However, this question is open for empirical verification.

When firms publish negative CSP disclosures, they may apply various strategies to attempt to preserve their legitimacy. In this research, we studied the extent to which firms 
CCIJ

25,2

from different cultural clusters used the legitimation strategies identified by Hahn and Lülfs (2014). These legitimation strategies can be categorized as either symbolic or substantive approaches. Substantive legitimation includes a real change of corporate aims, structures, actions or activities; symbolic strategies aim at changing stakeholder perceptions of these processes (Ashforth and Gibbs, 1990; Hahn and Lülfs, 2014).

The legitimation strategy applied most often was communicating corrective action, suggesting that the firms were prone to engage in substantive legitimation. Symbolic legitimation strategies, including rationalization or abstraction, were applied far less. Rarely did we observe a firm marginalizing the issue or trying to legitimize it by referencing an authority or benchmark.

However, detailed analyses of the corrective action approach show that this strategy can serve as either a substantive or a symbolic approach to legitimation. Our results show that a substantive strategy - i.e. giving a precise statement on how or when the problem was to be corrected - occurred in about one-third of the cases. Firms from Confucian Asian countries were strongly represented in this category. However, firms can also apply corrective action as a symbolic strategy; this is the case when the change or correction is imprecisely mentioned, suggested or held out prospectively. Firms from all three clusters used the symbolic approach to a similar degree.

A third way of using the corrective action strategy is to communicate a corrective action that has already been implemented, a tactic that is preferred by firms from Confucian Asian countries. They may consider this strategy to be effective in saving face, as it shows that the firm has already acted and has found a practical solution to curb the negative impact. However, communicating a completed corrective action risks giving the impression that the firm is trying to conceal the problem until they have applied a viable solution. This could counteract the principle of timeliness, which requests firms to disclose the information in temporal proximity to the actual events so that stakeholders can integrate it into their decision-making (GRI, 2015).

\section{Theoretical and practical implications}

Negative CSP carries risks and rewards that require further theoretical clarification. On the one hand, empirical research demonstrates that negative CSP creates idiosyncratic risk for companies (Mishra and Modi, 2013), and negative CSP disclosure may exacerbate these risks and give further ammunition to competitors and critics with ulterior motives (Dubbink et al., 2008). On the other hand, negative CSP provides an opportunity for confession and vulnerability, pulling back the untouchable aura that many firms convey in ways that build organization-public relationships, identification and trust. Then again, it might also provide an opportunity for more cynicism and skepticism. In addition, further attention is warranted for the role played by all of the legitimation strategies identified here in influencing these outcomes.

Further research examining CSP disclosures in relation to third-party verification and authentication gives us the opportunity to explore gaps, discrepancies, consistencies, shortcomings, omissions and over-disclosures, as well as the timing and sequence of negative CSP disclosures in relation to other sources. Each of these has a remarkable power to influence the corporate reputation, trust, legitimacy and source credibility of firms.

Practical implications can be derived for the GRI and other reporting initiatives. Demanding the disclosure of "positive and negative aspects of the organization's performance" (GRI, 2015, p. 17) is useful, yet what counts as negative aspects remains unclear. Thus, we suggest that the GRI offers a clear definition (as is presented in this paper). Hahn and Lülfs (2014) also outlined a scheme for disclosing negative incidents, comprised of an objective description of the negative aspect followed by an explanation providing context. Aside from these two steps (which should be made mandatory), firms can supplement a 
disclosure with an evaluation of the incident. Finally, consequences should clearly show which concrete corrective action will be or has been taken to resolve the situation, to allow traceability and to foster accountability.

\section{Limitations}

Our findings must be understood in the context of the study's limitations. First, our research only focused on negative CSP disclosed in the CSR reports, not actual negative CSP. Evaluating negative CSP across non-governmental organizations' (NGOs') reports, rating agencies (such as KLD), government agencies, the news media and corporate or industry archives has already begun (Lisbon and Heyes, 2019; Mishra and Modi, 2013; Sethi et al., 2017) and merits further research in the context of negative disclosures.

Second, we only analyzed reports by firms listed within the Forbes Global 2000 - that is, large international firms. Expectations regarding the sustainability of operations of such large firms may be similar (Hahn and Lülfs, 2014); thus, the differences between the clusters may even be larger if a sample of smaller firms was included. Therefore, analyzing reports from smaller firms is a rich area for future research.

Third, we focused on the GRI initiative, as it is the most widely used reporting framework and because the GRI explicitly requests balance as one of their quality principles. However, our contribution should not be limited to reports that adhere to GRI standards, but should apply to any CSR report that aims for transparency.

Fourth, we generated descriptive data; thus, inferences about effects are hypothetical. Despite research on the positive effects of two-sided communication (e.g. Bohner et al., 2003; Kamins and Assael, 1987) and proactive negative information (Wagner et al., 2009), the effect of negative CSP disclosures in CSR reports remains unknown, as does the test for contingent conditions, like culture and type of stakeholder. For example, institutional investors who have other information channels than less-powerful stakeholders may prefer that firms issue negative CSP disclosures to them privately, but not disclose them publicly. At the same time, actively disclosing negative aspects of CSP may be regarded as a positive transparency signal, helping organizations manage risk, develop reputations for accountability and avoid future issues.

\section{Conclusion}

Transparency is a key concept in CSR, and the principle of balance is a central aspect. Stakeholders are a firm's potential beneficiaries and risk-bearers (Post et al., 2002) and therefore are reasonably entitled to information about developments or activities that may affect their interests (Deegan and Rankin, 1996; Dubbink et al., 2008). Therefore, balance is a set principle of report quality specified by the GRI, put forth to enable informed assessment of a firm's overall performance. To reach this objective, we suggest that reporting initiatives like the GRI become more assertive and concrete when promoting this principle. Besides specifying that the report should disclose both favorable and unfavorable results, and that the disclosures should be presented in an easy-to-grasp format (GRI, 2015), the guidelines should be very clear that any material information concerning unmet goals or setbacks has to be disclosed.

As our data suggest, external assurance increases the disclosure of failures, shortcomings or setbacks, at least to some extent. Therefore, external assurance must be conducted more rigorously to substantially increase transparency. It should be mentioned that some critics argue that assurance itself lacks credibility, because it works more like an internal management tool seizing risks and issues than a practice enhancing transparency and sustainability accountability to external stakeholders (Fonseca, 2010). For the sake of
Corporate social responsibility reporting 
CCIJ 25,2

accountability and transparency, firms should not only be open to internally identifying critical issues but also to externally addressing them. Efforts such as Sethi et al.'s (2017) CSR Sustainability Monitor should help in this regard.

\section{Notes}

1. We use the term "CSR report" to refer to reports that include corporate disclosures on the social and environmental performance of a firm. Other frequently used terms are "sustainability report" and "responsibility report."

2. In the classification by Gupta et al. (2002), G/N Europe form two different cultural clusters. However, Germanic European societies are highly likely to be classified with the Nordic European cluster. Therefore, because the clusters are similar in the cultural dimension that is central to this research (individualism-collectivism), we combined these two cultural clusters into one.

3. This analysis does not include the five reports that only obtained third-party opinions.

\section{References}

Ashforth, B.E. and Gibbs, B.W. (1990), "The double-edge of organizational legitimation”, Organization Science, Vol. 1 No. 2, pp. 177-194.

Basu, K. and Palazzo, G. (2008), "Corporate social responsibility: a process model of sensemaking”, Academy of Management Review, Vol. 33 No. 1, pp. 122-136.

Bohner, G., Einwiller, S., Erb, H.-P. and Siebler, F. (2003), "When small means comfortable: relations between product attributes in two-sided advertising", Journal of Consumer Psychology, Vol. 13 No. 4, pp. 454-463.

Boiral, O. (2016), "Accounting for the unaccountable: biodiversity reporting and impression management", Journal of Business Ethics, Vol. 135 No. 4, pp. 751-768.

Bond, M.H. and Hwang, K.-k. (1986), "The social psychology of Chinese people”, in Bond, M.H. (Ed.), The Psychology of Chinese People, Oxford University Press, New York, N. Y, pp. 213-266.

Brown, N. and Deegan, C. (1998), "The public disclosure of environmental performance informationa dual test of media agenda setting theory and legitimacy theory", Accounting and Business Research, Vol. 29 No. 1, pp. 21-41.

Carroll, C.E. and Einwiller, S.A. (2014), "Disclosure alignment and transparency signaling in CSR reports", in Hart, R.P. (Ed.), Communication and Language Analysis in the Corporate World, IGI Global, Hershey, PA, pp. 249-270.

Carroll, C.E. and Olegario, R. (2019), "Pathways to corporate accountability: corporate reputation and its alternatives", Journal of Business Ethics, Online First, July 2019, doi: 10.1007/s10551-01904228-2.

Coombs, W.T. and Holladay, S.J. (2013), "The pseudo-panopticon: the illusion created by CSR-related transparency and the internet”, Corporate Communications: An International Journal, Vol. 18 No. 2, pp. 212-227.

Deegan, C. (2002), "The legitimizing effect of social and environmental disclosures - a theoretical foundation", Accounting, Auditing \& Accountability Journal, Vol. 15 No. 3, pp. 282-311.

Deegan, C., Cooper, B.J. and Shelly, M. (2006), "An investigation of TBL report assurance statements: UK and European evidence”, Managerial Auditing Journal, Vol. 21 No. 4, pp. 329-371.

Deegan, C. and Gordon, B. (1996), "A study of the environmental disclosure practices of Australian corporations", Accounting and Business Research, Vol. 26 No. 3, pp. 187-199.

Deegan, C. and Rankin, M. (1996), "Do Australian companies report environmental news objectively?", Accounting, Auditing \& Accountability Journal, Vol. 9 No. 2, pp. 50-67.

Devin, B. (2016), "Half-truths and dirty secrets: omissions in CSR communication", Public Relations Review, Vol. 42 No. 1, pp. 226-228. 
Dowling, G.R. and Pfeffer, J. (1975), "Organizational legitimacy: social values and organizational behavior”, Pacific Sociological Review, Vol. 18 No. 1, pp. 122-136.

Dubbink, G., Graafland, J. and van Liedekerke, L. (2008), "CSR, transparency and the role of intermediate organisations", Journal of Business Ethics, Vol. 2 No. 82, pp. 391-406.

Elving, W.J.L., Golob, U., Podnar, K., Ellerup-Nielsen, A. and Thomson, C. (2015), "The bad, the ugly and the good: new challenges for CSR communication", Corporate Communications: An International Journal, Vol. 20 No. 2, pp. 118-127.

Fonseca, A. (2010), "How credible are mining corporations' sustainability reports? A critical analysis of external assurance under the requirements of the international council on mining and metals", Corporate Social Responsibility and Environmental Management, Vol. 17 No. 6, pp. 355-370.

Forbes (2014), "Global 2000: the world's largest public companies", available at: https://www.forbes. com/global2000/list.

Freedman, M. and Jaggi, B. (2005), "Global warming, commitment to the Kyoto protocol, and accounting disclosures by the largest global public firms from polluting industries", The International Journal of Accounting, Vol. 40 No. 3, pp. 215-232.

GRI (2013), "The external assurance of sustainability reporting. Amsterdam”, available at: https:// www.globalreporting.org/resourcelibrary/GRI-Assurance.pdf.

GRI (2015), “G4 sustainability reporting guidelines. Amsterdam”, available at: https://www. globalreporting.org/standards/g4/Pages/default.aspx.

GRI and G\&A (2013), "Trends in external assurance of sustainability reports: spotlight in the USA", available at: https://www.globalreporting.org/resourcelibrary/GRI-Assurance-Survey-2013.pdf.

Gupta, V., Hanges, P.J. and Dorfman, P. (2002), “Cultural clusters: methodology and findings”, Journal of World Business, Vol. 37 No. 1, pp. 11-15.

Hahn, R. and Lülfs, R. (2014), "Legitimizing negative aspects in GRI-oriented sustainability reporting: a qualitative analysis of corporate disclosure strategies", Journal of Business Ethics, Vol. 123 No. 3, pp. 401-420.

Hofstede, G., Hofstede, G.J. and Minkov, M. (2010), Cultures and Organizations: Software of the Mind, 3rd ed., McGraw-Hill, New York etc.

Ho, D.Y.- F. (1976), “On the concept of face”, American Journal of Sociology, Vol. 81 No. 4, pp. 867-890.

Holder-Webb, L., Cohen, J.R., Nath, L. and Wood, D. (2009), "The supply of corporate social responsibility disclosures among U.S. firms", Journal of Business Ethics, Vol. 84 No. 4, pp. 497-527.

House, R., Hanges, P.J., Javidan, M., Dorfman, P.W. and Gupta, V. (2004), Culture, Leadership, and Organizations: The GLOBE Study of 62 Societies, SAGE, Thousand Oaks, CA.

Kamins, M.A. and Assael, H. (1987), "Two-sided versus one-sided appeals: a cognitive perspective on argumentation, source derogation, and the effect of disconfirming trial on belief change", Journal of Marketing Research, Vol. 24 No. 1, pp. 29-39.

Kaplan, S.E. and Ruland, R.G. (1991), "Positive theory, rationality, and accounting regulation", Critical Perspectives on Accounting, Vol. 2 No. 4, pp. 361-374.

KPMG (2013), "The KPMG survey of corporate responsibility reporting 2013", available at: https:// assets.kpmg/content/dam/kpmg/pdf/2015/08/kpmg-survey-of-corporate-responsibility-reporting2013.pdf.

KPMG (2015), "Currents of change. The KPMG survey of corporate responsibility reporting 2015", available at: https:/home.kpmg/content/dam/kpmg/pdf/2015/12/KPMG-survey-of-CR-reporting2015.pdf.

KPMG (2017), "The road ahead. The KPMG survey of corporate responsibility reporting 2017", available at: https:/home.kpmg/xx/en/home/insights/2017/10/the-kpmg-survey-of-corporateresponsibility-reporting-2017.html.
Corporate social responsibility reporting 
CCIJ

25,2

334

Kolk, A. (2005), "Environmental reporting by multinationals from the triad: convergence or divergence?", Management International Review, Vol. 45 No. 1, pp. 145-166.

Kolk, A. (2008), "Sustainability, accountability and corporate governance: exploring multinationals' reporting practices", Business Strategy and the Environment, Vol. 17 No. 1, pp. 1-15.

Liston-Heyes, C. and Ceton, G. (2009), "An investigation of real versus perceived CSP in S\&P 500 firms”, Journal of Business Ethics, Vol. 89 No. 2, pp. 283-296.

Mishra, S. and Modi, S.B. (2013), "Positive and negative corporate social responsibility, financial leverage, and idiosyncratic risk", Journal of Business Ethics, Vol. 117 No. 3, pp. 431-448.

Neu, D., Warsame, H. and Pedwell, K. (1998), "Managing public impressions: environmental disclosures in annual reports", Accounting, Organisations, and Society, Vol. 23 No. 3, pp. 265-282.

O'Donovan, G. (2002), "Environmental disclosures in the annual report: extending the applicability and predictive power of legitimacy theory", Accounting, Auditing, and Accountability Journal, Vol. 15 No. 3, pp. 344-371.

Oyserman, D., Coon, H.M. and Kemmelmeier, M. (2002), "Rethinking individualism and collectivism: evaluation of theoretical assumptions and meta-analyses", Psychological Bulletin, Vol. 128 No. 1, pp. 3-72.

Post, J.E., Preston, L.E. and Sachs, S. (2002), Redefining the Corporation: Stakeholder Management and Organizational Wealth, Stanford Business Books, Stanford University Press, Stanford, CA.

Potter, J.W. and Levine-Donnerstein, D. (1999), "Rethinking validity and reliability in content analysis", Journal of Applied Communication Research, Vol. 27 No. 3, pp. 258-284.

Rawlins, B. (2009), "Giving the emperor a mirror: toward developing a stakeholder measurement of organizational transparency", Journal of Public Relations Research, Vol. 21 No. 1, pp. 71-99.

Reid, E.M. and Toffel, M.W. (2009), "Responding to public and private politics: corporate disclosure of climate change strategies", Strategic Management Journal, Vol. 30 No. 11, pp. 1157-1178.

Sethi, S.P., Rovenpor, J.L. and Demir, M. (2017), "Enhancing the quality of reporting in corporate social responsibility guidance documents: the roles of ISO 6000, Global Reporting Initiative and CSRSustainability Monitor", Business and Society Review, Vol. 122 No. 2, pp. 139-163.

Skowronski, J.J. and Carlston, D.E. (1989), "Negativity and extremity biases in impression formation: a review of explanations", Psychological Bulletin, Vol. 105 No. 1, pp. 131-142.

Smith, R.E. and Hunt, S.D. (1978), "Attributional processes and effects in promotional situations", Journal of Consumer Research, Vol. 5 No. 3, pp. 149-158.

Suchman, M.C. (1995), "Managing legitimacy: strategic and institutional approaches", Academy of Management Review, Vol. 20 No. 3, pp. 571-610.

Talbot, D. and Boiral, O. (2018), "GHG reporting and impression management: an assessment of sustainability reports from the energy sector", Journal of Business Ethics, Vol. 147 No. 2, pp. 367-383.

Ting-Toomey, S. and Kurogi, A. (1998), "Facework competence in intercultural conflict: an updated face-negotiation theory", International Journal of Intercultural Relations, Vol. 22 No. 2, pp. 187-225.

Triandis, H.C. (1995), Individualism \& Collectivism, Westview Press, Boulder, CO.

Varner, I. and Beamer, L. (2005), Intercultural Communication in the Global Workplace, 3rd ed., McGraw-Hill, Boston, MA.

Waddock, S. and Googins, B.K. (2011), "The paradoxes of communicating corporate social responsibility",in Ihlen, Ø., Bartlett, J. and May, S. (Eds.), The Handbook of Communication and Corporate Social Responsibility, Wiley-Blackwell, Chichester, pp. 23-43.

Wagner, T., Lutz, R.J. and Weitz, B.A. (2009), "Corporate hypocrite: overcoming the threat of inconsistent corporate social responsibility perceptions", Journal of Marketing, Vol. 73 No. 6, pp. 77-91. 
Wilson, M.J. (2003), Independent Assurance on Corporate Sustainability Reports, University of Calgary, Calgary.

Corporate

social

Wood, D.J. (2010), "Measuring corporate social performance: a review", International Journal of Management Reviews, Vol. 12 No. 1, pp. 50-84.

Zhang, Y.B., Lin, M.- C., Nonaka, A. and Beom, K. (2005), "Harmony, hierarchy and conservatism: a cross-cultural comparison of Confucian values in China, Korea, Japan, and Taiwan", Communication Research Reports, Vol. 22 No. 2, pp. 107-115.

(The Appendix follows overleaf) 


\begin{tabular}{lll}
\hline Variable & Categories & Source \\
\hline Manifest categories & & \\
Country & Country where firm is headquartered & Authors \\
Cultural cluster & Anglo; Confucian Asia; G/N Europe & Gupta et al. (2002) \\
Industry sector & Financial service providers, insurances; & Forbes; \\
& telecommunication, computer, electronics; & condensed by \\
& retail, consumer goods; automobile, & authors
\end{tabular}

Adherence to GRI

External assurance

Number of pages

Number of relevant pages

Proportion of negative information in page

Proportion of total negative content in report

\section{Latent categories}

New aspect

Topic area

\section{Legitimation strategies}

\section{Corrective action}

0) No corrective action mentioned

1) Corrective action only imprecisely mentioned, suggested or held out prospectively

2) Precise corrective action mentioned or problem already partly corrected 3) Problem has been corrected
Table AI.

Category scheme for content analysis transportation; oil and gas, energy, raw materials; chemicals and pharmaceuticals; conglomerates, construction

No, or not mentioned; yes, but version not specified; adherence to G3/G3.1 or G4 explicitly mentioned

No, the report is not externally assured (no mention of assurance); yes, the report is externally assured

Total number of pages in report

Pages that may contain negative content (excluding title and back page, table of contents, dividing pages, pages with tables or figures more than half a page, publishing information/flag)

Relative figure (e.g., $5 \%=0.05$ )

Authors

Sum of proportions of negative information in Authors the page divided by the number of relevant pages

New aspect disclosed; same aspect had been mentioned and coded as negative before Economic; environment; labor practices and working conditions; human rights; society; product responsibility; other (up to seven subcategories for each topic area)

1) We develop plans to close the gaps, implement the plans and review plan implementation performance. (Chevron, p. 2) // The overall RTP program is being reviewed to better understand this change and set new recycling goals for the campus (Cisco, p. 109) 2) Some locations expose our workforce and their families to a higher risk of infectious disease, so we have established a structured program for infectious disease control to monitor and address related issues

(ExxonMobil, p. 16)

3) We did an investigation and placed clean impervious sheets to cover all vehicles transporting waste out of the sites and did not encounter any further complications (Sun Hung Kai Properties, p. 43)
Authors

GRI 3.1 and four; adapted by authors

Hahn and Lülfs (2014); authors 
Variable
Rationalization
0) No
1) Yes, justifying negative aspects by
highlighting benefits, functions or purposes (instrumental)

2) Yes, justifying neg. aspects by emphasizing some form of "normal" or "natural" behavior or circumstances (theoretical)

\section{Abstraction}

0) $\mathrm{No}$

1) Yes, generalizing negative aspects as being prevalent (typically) throughout a whole industry

\section{Marginalization}

0) No

1) Yes, rendering negative aspects nonrelevant, unimportant, or negligible

\section{Authorization}

0) No

1) Yes, specifically mentioning a

legitimizing authority, regulation, law, benchmark or industry standard

\section{Categories}

1) In 2014, total emissions in our production network amounted to $1,369,877$ tons of $\mathrm{CO}_{2}$ (2013: 1,322,316 tons). This is only a slight increase of $3.6 \%$ in spite of a significant increase of $7.6 \%$ in production volume (BMW, p. 82)

2) As a large financial services institution, we use a great deal of paper in our offices and in client materials. (Royal Bank of Canada, p. 39) // Global warming is most probably causing an increase in extreme weather events, such as heat waves, droughts, floods and tropical storms, which affect the insurance industry through payments for loss and damage (Allianz, p. 22)

1) Discussions on nuclear power, energy prices, the environment and sustainability affect the reputation of many energy utilities. As a large, DAX-listed company E.ON is particularly exposed in Germany and is always mentioned in public debates on energy supply topics. (E.ON, p. 17) // The ongoing industry challenge is to achieve growth $-\mathrm{a}$ concern we share with many others in the telecom sector (Teliasonera, p. 5)

1) Although our chemical waste generated increased, we sent just $5 \%$ of that waste to landfill. (Intel, p. 5) // During the fiscal year ended March 31, 2013, there were no environmental-related incidents at the parent company. There was, however, one small environmental-related incident reported by one of our subsidiaries and affiliates (Mitsui and Co., p. 62)

1) According to external studies, nearly 75 percent of project delays are due to nontechnical issues such as changes in regulations, the political environment or stakeholder issues. (Exxon Mobil, p. 45) // The lack of industry-wide standards, however, hinders systematic monitoring. For example, we cannot be certain that human and workers' rights are respected in all of the countries from which we source coal and uranium (E.ON, p. 159)
Source

Hahn and Lülfs

(2014)

Hahn and Lülfs (2014)

Hahn and Lülfs (2014)

Hahn and Lülfs (2014)
Corporate social responsibility reporting

337 